\title{
TERRITORIALIZAÇÃO DA AÇÃO PÚBLICA NO MEIO OESTE CONTESTADO: UMA FERRAMENTA PARA O ENFRENTAMENTO DA POBREZA?
}

\section{TERRITORIALIZATION OF PUBLIC ACTION IN MEIO OESTE CONTESTADO TERRITORY: A TOOL FOR TACKLING POVERTY?}

\author{
TERRITORIALIZACIÓN DE LA ACCIÓN PÚBLICA EN EL MEDIO OESTE \\ CONTESTADO: ¿UNA HERRAMIENTA DE LUCHA CONTRA LA POBREZA?
}

\author{
Andréia Tecchio ${ }^{1}$ \\ ORCID: 0000-0003-0283-9996 \\ Ademir Antonio Cazella ${ }^{2}$ \\ ORCID: 0000-0002-4457-4853
}

Submissão: 15/06/2020 / Aceito: 30/09/2020 / Publicado: 30/06/2021

\begin{abstract}
Resumo
O Brasil inovou ao territorializar a ação pública de enfrentamento da pobreza com a criação do Programa Desenvolvimento Sustentável dos Territórios Rurais (Pronat) em 2003 e do Programa Território da Cidadania (PTC) em 2008. A ação pública territorializada busca a aplicação articulada de um conjunto de políticas públicas num território para tratar de forma diferenciada determinados segmentos sociais, tendo sua gestão compartilhada por atores da sociedade civil e do Estado. A partir dessa perspectiva, este artigo analisa os entraves e as potencialidades do Pronat e do PTC no enfrentamento da pobreza no Território Meio Oeste Contestado, composto por 29 municípios da região Oeste de Santa Catarina. Para tanto, realizou-se pesquisa documental e de campo em dez municípios, na qual foram entrevistados 38 atores institucionais. Os resultados indicam que a territorialização da ação pública não foi acompanhada de uma ferramenta de planejamento das ações de enfrentamento da pobreza. O Pronat beneficiou agricultores familiares ligados a movimentos sociais e sindicais do campo e inseridos em cadeias de comercialização. O PTC melhorou as condições de vida das populações pobres, todavia, não foi suficiente para fazer com que superassem a condição de pobreza. A extinção do Ministério do Desenvolvimento Agrário em 2016 implicou na descontinuidade desses programas, mas o aprendizado social da sua implementação pode embasar futuras ações públicas de desenvolvimento territorial com foco no enfrentamento da pobreza rural.
\end{abstract}

Palavras-chave: Ação Pública, Pobreza, Territorialização, Descentralização.

\footnotetext{
${ }^{1}$ Doutora em Ciências Sociais pelo Programa de Pós-Graduação de Ciências Sociais em Desenvolvimento, Agricultura e Sociedade, da Universidade Federal Rural do Rio de Janeiro (CPDA/UFRRJ). Pós-Doutoranda no Programa de Pós-Graduação em Agroecossistemas, na Universidade Federal de Santa Catarina (PPGA/UFSC). Florianópolis, Santa Catarina, Brasil. Correio eletrônico: deiatecchio@ yahoo.com.br. ${ }^{2}$ Doutor em Ordenamento Territorial junto ao Centre d'Etudes Supérieures d'Aménagement,Tours/França. Professor titular do PPGA/UFSC. Florianópolis, Santa Catarina, Brasil. Correio eletrônico: cazella@ufsc.com.
} 


\begin{abstract}
Brazil innovated by territorializing public action to tackle poverty with the creation of the Sustainable Development for Rural Territories Program (Pronat) in 2003 and the Territory of Citizenship Program (PTC) in 2008. Territorialized public action seeks the articulated application of a set of public policies in a territory to address certain social segments differently, with their management shared by civil society and state actors. From this perspective, this article analyzes the obstacles and potentialities of Pronat and PTC in confronting poverty in the Meio Oeste Contestado Territory, composed of 29 municipalities in the western region of Santa Catarina. For this purpose, documental and field research were carried out in ten municipalities, with interviews with 38 institutional actors. The results indicate that the territorialization of public action was not accompanied by a planning tool of poverty tackling actions. Pronat benefited family farmers linked to rural unions and social movements and those inserted in marketing chains. The PTC improved the living conditions of the poor populations, however, it was not enough to make them overcome the condition of poverty. The extinction of the Ministry of Agrarian Development in 2016 meant that these programs were discontinued, but the social learning of their implementation may support future public actions for territorial development with a focus on tackling rural poverty.
\end{abstract}

Keywords: Public Action, Poverty, Territorialization, Decentralization.

\title{
Resumo
}

Brasil ha innovado territorializando la acción pública de lucha contra la pobreza con la creación del Programa Desarrollo Sustentable en los territorios rurales (Pronat) en 2003 et del Programa Territorio de la Ciudadanía (PTC) en 2008. La acción pública territorializada busca la aplicación articulada de un conjunto de políticas públicas en un territorio con el objetivo de tratar de maneras distintas determinados segmentos sociales. Su gestión es compartida entre atores de la sociedad civil y del Estado. Desde esa perspectiva, este artículo analiza los obstáculos y las capacidades del Pronat y del PTC en la lucha contra la pobreza en el Territorio Meio Oeste Contestado, compuesto por 29 municipios de la región Oeste de Santa Catarina. Para estos fines, se realizó una investigación documental y en terreno en diez municipios a partir de entrevistas con 38 actores institucionales. Los resultados indican que la territorialización de la acción pública no presentó una herramienta de planificación de acciones de lucha contra la pobreza. El Pronat benefició a los agricultores familiares vinculados a los movimientos sociales y sindicales del campo y en cadenas de comercialización. A su vez, El PTC ha mejorado las condiciones de vida de los pobres, sin embargo no lo suficiente para superar la pobreza. La extinción del Ministerio de Desarrollo Agrario en 2016 tuvo como consecuencia la discontinuidad de esos programas, aunque el aprendizaje social de su implementación pueda fundamentar las próximas acciones públicas de desarrollo territorial centradas en la lucha de la pobreza en el futuro.

Palabras clave: Acción pública, pobreza, Territorialización, Descentralización

\section{INTRODUÇÃO}

No Brasil, a territorialização da ação pública iniciou no primeiro governo de Luiz Inácio Lula da Silva (2003-2010), por meio da recém-criada Secretaria de Desenvolvimento 
Territorial (SDT), vinculada ao Ministério do Desenvolvimento Agrário (MDA) ${ }^{3}$. Para tanto, foram criados os territórios rurais de identidade, que se beneficiavam do Programa de Desenvolvimento Sustentável dos Territórios Rurais (Pronat). Esse Programa visava promover dinâmicas socioeconômicas endógenas nos territórios a serem impulsionadas por estratégias de desenvolvimento rural, dentre as quais, a formulação e implantação de projetos territoriais estratégicos (LEITE, 2013a). O Pronat repassava recursos financeiros públicos não reembolsáveis para projetos produtivos de caráter intermunicipal, que atendessem coletivos de agricultores familiares e povos tradicionais. De acordo com Bonnal (2013), o Pronat contemplava a questão da pobreza rural de forma indireta, por meio da ampliação das atividades econômicas e da prática da solidariedade entre o público assistido.

A temática da pobreza foi melhor articulada às políticas públicas territorializadas em 2008, quando o Governo Federal criou o Programa Territórios da Cidadania (PTC), vinculado à Casa Civil e com participação do então MDA na sua gestão e execução. Durante o processo de formalização dos territórios rurais de identidade, dirigentes da SDT perceberam que determinados territórios possuíam economia mais frágil em relação aos demais e que havia necessidade de uma atenção emergencial com ações melhor articuladas (BONNAL, 2013). Assim, o PTC é um desdobramento do Pronat, cujo propósito principal consistiu em articular um amplo conjunto de políticas públicas e de ações oriundas de diferentes ministérios em torno de um mesmo território (BONNAL, 2013; BONNAL, KATO, 2011). O objetivo principal do PTC era enfrentar a pobreza por meio da promoção do desenvolvimento econômico com base na geração de trabalho e de renda e na universalização dos programas básicos de cidadania (DELGADO, LEITE, 2011).

A territorialização de ações públicas permite abordar a pobreza em espaços precisos, beneficiando de forma diferenciada os setores mais sensíveis e vulneráveis (SÉCHET, 1996). Com base nesse pressuposto, o objetivo deste artigo consiste em analisar os entraves e as potencialidades da aplicação territorializada dos recursos financeiros do Pronat e do PTC, com foco na forma de como esses recursos foram utilizados para o enfrentamento da pobreza.

\footnotetext{
${ }^{3}$ Criado em 1999, no governo de Fernando Henrique Cardoso (1995-2002), o MDA foi extinto por meio da Medida Provisória $n^{\circ}$ 726, de 12 de maio de 2016, pelo então Presidente interino Michel Temer (2016-2018), no poder devido ao afastamento da Presidente Dilma Rousseff (2011-2016). Essa mesma Medida transformou o Ministério do Desenvolvimento Social e Combate à Fome em Ministério de Desenvolvimento Social e Agrário. Ademais, determinou que uma parte das atividades do MDA fosse transferida para o novo Ministério e outras atribuições fossem incorporadas à Casa Civil.
} 
Em que pese o esgotamento dessa iniciativa na atual conjuntura político-institucional brasileira, a análise desse processo que perdurou por pouco mais de uma década, representa uma oportunidade para retomadas vindouras da perspectiva territorial de gestão e implementação de políticas públicas.

Para responder ao objetivo deste artigo, adotamos o contexto empírico do Território Meio Oeste Contestado, composto por 29 municípios e localizado na região Oeste de Santa Catarina. A Figura 01 apresenta a localização geográfica de Santa Catarina no Brasil, do Território no estado, bem como dos municípios que o integram ${ }^{4}$. Figura 01: localização geográfica de Santa Catarina no Brasil, do Território no estado
e dos municípios no interior do Território

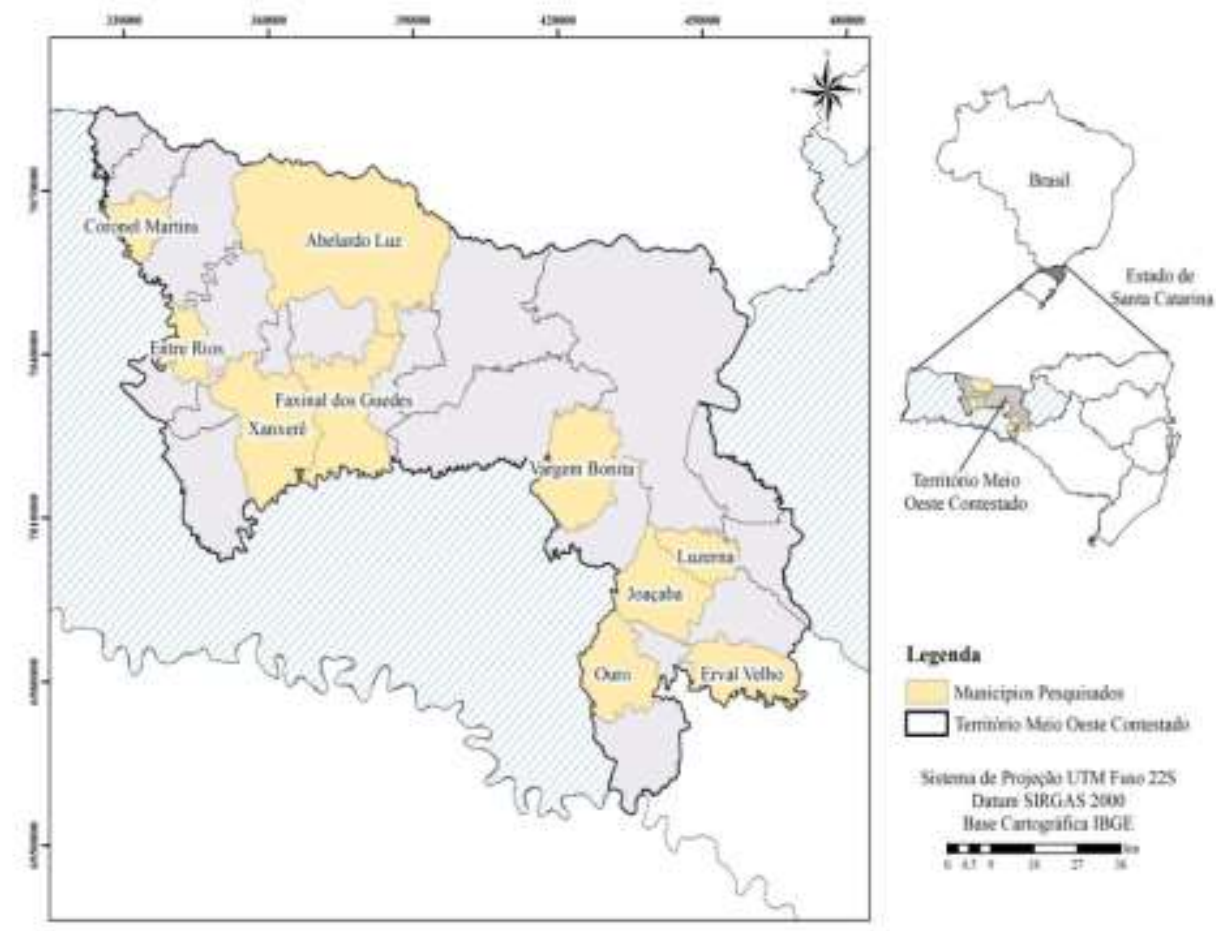

Fonte: Adaptado de IBGE (2017).

\footnotetext{
${ }^{4}$ Os seguintes municípios integram o Território Meio Oeste Contestado: Abelardo Luz, Água Doce, Bom Jesus, Capinzal, Catanduvas, Coronel Martins, Entre Rios, Erval Velho, Faxinal dos Guedes, Galvão, Herval D'Oeste, Ibicaré, Ipuaçu, Joaçaba, Jupiá, Lacerdópolis, Lajeado Grande, Luzerna, Marema, Ouro, Ouro Verde, Passos Maia, Ponte Serrada, São Domingos, Treze Tílias, Vargeão, Vargem Bonita, Xanxerê e Xaxim.
} 
Os procedimentos metodológicos contemplam pesquisas documental e de campo. $\mathrm{O}$ primeiro consistiu em análise de textos, documentos, leis, Matriz de Ações ${ }^{5}$ do Pronat, materiais de divulgação e atas de reuniões referentes ao Pronat e ao PTC, elaborados por gestores e consultores do Governo Federal, em especial do MDA/SDT, e do Território Meio Oeste Contestado. A análise documental subsidiou, principalmente, o entendimento das mudanças institucionais realizadas para a implementação das ações públicas territorializadas, bem como a aplicação dos recursos financeiros. Para tanto, os períodos analisados compreenderam os de execução do Pronat, de 2003 a 2015, e do PTC de 2008 a 2015.

A pesquisa de campo foi realizada em dois momentos, sendo o primeiro em setembro e outubro de 2014 e o segundo, de natureza complementar, em abril e maio de 2016, em dez municípios do Território Meio Oeste Contestado, destacados na Figura 01. Esses municípios foram selecionados com base nos critérios de diversidade de contextos sociais, econômicos e demográficos. No total, 38 atores institucionais das seguintes organizações foram entrevistados: administrações municipais (prefeitos, técnicos, secretários municipais, assistentes sociais); instituições intermunicipais (gestores de Associações de Municípios AM, Agências de Desenvolvimento Regional e consórcio público intermunicipal); delegados do Colegiado de Desenvolvimento Territorial (Codeter) representantes da sociedade civil e do governo e assessores territoriais que atuaram na esfera federal, estadual e territorial. Os atores institucionais foram questionados principalmente em relação à aplicação dos recursos financeiros do Pronat e do PTC e ao planejamento e uso desses recursos como estratégia de enfrentamento da pobreza 6 .

Para além desta introdução, o artigo está dividido em quatro seções principais. A primeira aborda a territorialização como uma ferramenta inovadora na aplicação de ações públicas para tratar problemas na escala territorial. A segunda e a terceira, respectivamente,

\footnotetext{
${ }^{5}$ A Matriz de Ações foi um documento da política pública de desenvolvimento territorial, que continha as metas e os recursos financeiros destinados pelos ministérios para serem executados nos territórios rurais de identidade e da cidadania.

${ }^{6}$ A elaboração deste artigo baseia-se em temas abordados pela primeira autora na tese de doutorado, desenvolvida junto ao Programa de Pós-Graduação em Ciências Sociais em Desenvolvimento, Agricultura e Sociedade, da Universidade Federal Rural do Rio de Janeiro (CPDA/UFRRJ). Além disso, apoia-se nos resultados parciais do projeto de pesquisa "Estudo de iniciativas de descentralização de políticas públicas voltadas ao desenvolvimento rural em Santa Catarina", desenvolvido no âmbito do Laboratório de Estudos da Multifuncionalidade Agrícola e do Território (Lemate), da Universidade Federal de Santa Catarina (UFSC), financiado pela Fundação de Amparo à Pesquisa e Inovação do Estado de Santa Catarina (Fapesc), do qual os autores participaram.
} 
discutem a governança e a aplicação territorializadas dos recursos financeiros do Pronat. A quarta contempla a territorialização das ações do PTC, enfatizando a análise dos espaços nos quais ocorreu a discussão para a sua implementação. Por fim, nas considerações finais, elabora-se uma síntese dos limites e das potencialidades concernentes ao planejamento das ações públicas territorializadas de enfrentamento da pobreza.

\section{A TERRITORIALIZAÇÃo DA AÇÃo PÚBLICA GOVERNAMENTAL}

A territorialização da ação pública surgiu na França, baseada nas reflexões sobre a gestão das políticas públicas no contexto da crise econômica e social da década de 1980 , associada ao surgimento de mudanças institucionais, com destaque para o início do processo de descentralização do Estado, influenciando significativamente a forma de gestão pública (DURAN, 2011). A territorialização da ação pública se consolidou no decorrer da década de 1990 e impulsionou coletividades territoriais (instâncias públicas mais próximas da população) e os serviços públicos descentralizados ${ }^{7}$. Ainda segundo Duran (2011), essas coletividades, por sua vez, passaram a representar um novo mecanismo de proximidade com o território, concebido como o espaço onde os problemas públicos se inscrevem e também o lugar privilegiado para o seu tratamento.

No Brasil, a noção de território passou a orientar a intervenção pública no meio rural na década de 1990, estando relacionada principalmente à descentralização de políticas públicas após a redemocratização do país, que teve como marco, a promulgação da Constituição Federal em 1988 (FAVARETO, 2010). Este autor lembra que, na perspectiva da descentralização, o Estado deve dar condições para que os atores implicados com a política participem da sua gestão.

Para Lascoumes e Le Galès (2012), a ação pública considera um conjunto de interações que tratam das transformações concernentes à maneira de elaborar e de implementar as políticas públicas. Nesse sentido, para Romano (2009), a ideia da ação pública pressupõe que as políticas não são elaboradas apenas pelo Estado, mas a partir do

\footnotetext{
7 A descentralização do Estado francês dos anos 1980 consistiu, principalmente, na criação de uma nova instância administrativa (Regiões), com eleição de deputados regionais, acima dos Departamentos já existentes, geridos por conselheiros departamentais, também, eleitos por sufrágio universal. As denominadas "coletividades territoriais" incluem, portanto, as Regiões, os Departamentos e os Municípios, bem como distintas formas de "agrupamenos" formais de municípios com o propósito de implementar políticas públicas.
} 
envolvimento de um amplo conjunto de atores estatais e não estatais, que agem por grupos de interesse.

A implementação de ações territorializadas implica em reestruturações institucionais. Uma delas concerne à articulação de diversas ações públicas em um mesmo espaço geográfico para o tratamento de problemas públicos (DOUILLET, 2005; HASSENTUEFEL, 1998). Para tanto, segundo Jaillet (2009), é preciso identificar a singularidade dos territórios e adequar as ações às suas especificidades, bem como construir normas específicas ao contexto local, por meio de contratos e negociações com os atores do território.

A outra reestruturação institucional diz respeito às reformas dos serviços do Estado, imprescindíveis para a criação de um fórum de discussão que conte com a participação de atores de diferentes instituições e universos sociais. O fórum deve contemplar a participação de atores que são relevantes para a política pública, bem como a construção de novos modelos de ação pública, a exemplo de contratos ou parcerias, de forma a gerar uma nova relação entre os atores da ação pública territorial (HASSENTUEFEL, 1998). O propósito consiste em agregar localmente interesses organizacionais específicos e implementar procedimentos de tratamento de determinados problemas por meio da representação que contemple diversos atores (MAILLARD, ROCHÉ, 2005). De certa maneira, a participação das coletividades territoriais permite um tratamento mais justo das demandas sociais (FAURE, 2011).

A territorialização da ação pública tem como centro estratégico de tomada de decisão e de ação esferas mais abrangentes - nacional ou estadual - que estão fora da escala territorial. Por conseguinte, o principal desafio do poder público consiste em priorizar as ações públicas mais adequadas a resoluções dos problemas, considerando as especificidades do território. Esse processo pode induzir dinâmicas que levam tanto a valorização quanto a desvalorização do território, em função da qualidade e dos tipos de serviços públicos que são prestados, bem como dos acertos e inadequações das ações que são territorializadas (DELGADO, GRISA, 2015).

A partir dessas reflexões, entendemos por territorialização da ação pública a implementação articulada de um conjunto de políticas públicas num território, por meio da concertação entre gestores públicos e atores da sociedade civil para a sua gestão social. Sob essa perspectiva, a territorialização da ação pública implica em mudanças institucionais que permitam abordar problemas em espaços precisos, para tratar de forma diferenciada 
determinados segmentos sociais, via adequação das políticas às suas especificidades. Essa noção orientou o estudo da aplicação territorializada dos recursos financeiros do Pronat e do PTC, em relação ao enfrentamento da pobreza no Território Meio Oeste Contestado.

\section{INSTITUCIONALIDADES E GOVERNANÇA NO TERRITÓRIO RURAL DE IDENTIDADE}

A territorialização das ações do Pronat implicou em mudanças institucionais, como a criação de um Codeter em cada território. Segundo os atores entrevistados que participaram da gestão da política territorial (delegados e assessores territoriais) no Meio Oeste Contestado, este Colegiado foi composto por "delegados", sendo dois terços da sociedade civil com vínculos com a agricultura familiar e um terço de diversos segmentos do poder público ligado ao desenvolvimento rural. No conjunto, esses delegados pertenciam a municipalidades de três Associações de Municípios: a Associação de Municípios do Alto Irani (AMAI), a Associação dos Municípios do Meio Oeste Catarinense (AMMOC) e a Associação de Municípios do Noroeste Catarinense (AMNoroeste).

O Codeter era a instância máxima de discussão e de deliberação dos territórios rurais de identidade, pois nesse espaço eram estabelecidas e negociadas as regras e as normas para a implementação de projetos de desenvolvimento territorial. Outra competência dessa institucionalidade consistia em analisar e aprovar o Plano Territorial de Desenvolvimento Rural Sustentável (PTDRS), com intuito de orientar ações de desenvolvimento a serem financiadas pelo Pronat (MDA, 2006; 2005). De acordo com atas de reuniões do Colegiado Territorial e entrevistas com atores implicados na gestão da política territorial, o Meio Oeste Contestado iniciou a elaboração do PTDRS, mas não o concluiu.

No âmbito do Codeter, outras duas institucionalidade foram criadas. O Núcleo Dirigente tinha como atribuição apoiar ações da instância colegiada, como reuniões, construção e implementação do PTDRS e de projetos territoriais; orientar os trabalhos do assessor técnico, bem como enviar projetos aprovados pelo Colegiado às instâncias competentes. Já o Núcleo Técnico foi composto por técnicos das ciências agrárias e tinha a função de prestar apoio técnico às atividades do Colegiado Territorial, como análise de projetos que visavam à obtenção de financiamento do Pronat, antes da sua apreciação no Codeter (DELGADO; GRISA, 2014). 
Apesar de novas institucionalidades terem sido criadas, o Governo Federal não reconheceu os territórios rurais enquanto unidades administrativas para a aplicação de ações territorializadas. Ou seja, não instituiu um marco legal que garantisse aos territórios segurança e validade jurídica para a realização de algumas de suas iniciativas, o que Delgado e Grisa (2015) chamaram de "incompletude" da política. Na prática, isso impôs uma importante dificuldade para a aplicação dos recursos financeiros de projetos do Pronat aprovados pelos Codeter (DELGADO, GRISA, 2014; 2013; MEDEIROS, DIAS, 2011). A execução dos projetos dependia do estabelecimento de parcerias entre a SDT e instituições públicas municipais ou estaduais. A forma legal que o MDA encontrou para repassar a infraestrutura rural financiada pelo Pronat foi o estabelecimento de contratos de repasse ${ }^{8}$, que é um instrumento administrativo que permite a execução descentralizada de um objeto de interesse recíproco. Os recursos financeiros são transferidos por meio de uma instituição financeira pública federal, que atua como mandatária da União.

No Território Meio Oeste Contestado, ao mesmo tempo em que elaboravam o projeto a ser financiado pelo Pronat, as organizações da sociedade civil negociavam a sua execução com a prefeitura do município onde a infraestrutura seria alocada. Concluída a execução da obra ou a aquisição do equipamento, a prefeitura repassava para os beneficiários por meio de um contrato de repasse. Nesse processo, as administrações municipais, na maioria das vezes, enfrentavam dificuldades ou entraves relativos à viabilização dos custos operacionais para a elaboração dos projetos técnicos, disponibilidade de profissionais técnicos para qualificar os procedimentos burocráticos e o atendimento dos diversos requisitos legais necessários à concretização dos projetos. Essas dificuldades foram relatadas nas entrevistas pela maioria dos prefeitos, delegados do Codeter e assessores territoriais que participaram da pesquisa de campo, além de registros em documentos e textos elaborados pelo Núcleo Dirigente.

Para os beneficiários do Pronat, o estabelecimento de contratos de repasse dificultou o uso da infraestrutura financiada na forma e no período estabelecido, segundo informações prestadas por assessores territoriais. No município de Coronel Martins, por exemplo, um veículo financiado pelo Pronat em 2007 foi destinado por meio de contrato de repasse para uso do Instituto de Cooperação da Agricultura Familiar de Santa Catarina. Todavia, a gestão

\footnotetext{
8 A União regulamentou o contrato de repasse por meio dos Decretos $n^{\circ} 6.170$, de 25 de julho de 2007 e $n^{\circ}$ 8.180, de 30 de dezembro de 2013.
} 
municipal de um mandato posterior ao da efetivação do projeto, entendeu que o veículo fazia parte do seu patrimônio e anulou o referido contrato. Em Joaçaba, a administração municipal reivindicou na Justiça a gestão do centro de comercialização de produtos da agricultura familiar financiado pelo Pronat. A Promotoria Pública deu ganho de causa à prefeitura, pois era esta que pagava as despesas de luz e água. O uso de infraestruturas adquiridas com recursos do Pronat por prefeituras foi verificado também por Barbosa, Zimmermann e Tecchio (2013) no Território Serra Geral, em Minas Gerais.

No Meio Oeste Contestado, agroindústrias financiadas pelo Pronat para grupos de famílias de agricultores enfrentavam diversos problemas para entrar em funcionamento. Esse tipo de problema já fora constatado por Mattei e Cazella (2009) referente a agroindústrias financiadas pelo Pronaf Infraestrutura e Serviços Municipais (Proinf) ${ }^{9}$, uma modalidade do Programa Nacional de Fortalecimento da Agricultura Familiar (Pronaf), que precedeu o Pronat. No entendimento da maioria dos atores institucionais entrevistados, algumas agroindústrias foram concebidas para atender demandas municipais, porém sem uma análise consistente sobre os canais de comercialização dos produtos agropecuários processados. Logo, para viabilizá-las, a produção deveria ser comercializada regionalmente. $\mathrm{Na}$ época ${ }^{10}$, os produtos industrializados de origem animal só poderiam ser comercializados fora do município se fossem fiscalizados pelo Sistema de Inspeção Estadual (SIE) ou Sistema de Inspeção Federal (SIF), o que exigia aumento da estrutura física e da produção da matériaprima.

No município de Faxinal dos Guedes foi construído um entreposto para beneficiamento de mel, que estava inoperante. Os delegados do Codeter optaram por construí-lo naquele município, devido à sua localização em relação aos demais municípios do Território. Em função de o estabelecimento estar próximo da BR 282, o transporte da matéria-prima até o entreposto para ser processada e embalada, bem como do produto pronto para ser comercializado, seria facilitado. A compra de equipamentos necessários para o

\footnotetext{
${ }^{9}$ O Proinf foi instituído em 1996 e almejava a melhoria das condições de infraestrutura e de produção em municípios rurais onde os agricultores familiares tinham uma presença significativa. Os municípios eram escolhidos com base em um conjunto de critérios, visando contemplar os mais pobres, os mais agrícolas e os menos populosos (FAVARETO, 2010; MATTEI, CAZELLA, 2009; ABRAMOVAY, 2001).

${ }^{10}$ Em Santa Catarina, os produtos que possuem o Sistema de Inspeção Municipal (SIM) passaram a ter permissão para ser comercializados nos municípios integrantes da Associação de Municípios em 2018, com a aprovação da Lei 17.515.
} 
funcionamento do entreposto foi negociado com uma gestão municipal, mas que não continuou na administração, não obstante, os sucessores não cumpriram o acordo. Os possíveis municípios beneficiados não aportaram recursos financeiros, pois como mencionado anteriormente, os territórios não possuíam institucionalidade jurídica para receber recursos financeiros dos municípios que os integravam. As dificuldades relacionadas ao entendimento e implementação territorializadas das ações no Pronat no Meio Oeste Contestado também foram identificadas por Oliveira et. al., (2015).

Não obstante, outros entraves foram observados na aplicação dos recursos financeiros do Pronat no Território pesquisado. No nosso entendimento, a inexistência do PTDRS e a ineficácia do Núcleo Técnico propiciaram a aprovação no Codeter de projetos técnicos sem que sua viabilidade econômica estivesse demonstrada. De acordo com a maioria dos atores institucionais inqueridos, muitas vezes, o tempo entre a data da divulgação da existência de recursos financeiros pelo MDA e a data limite para protocolar os projetos, não permitia que eles fossem discutidos com profundidade entre o grupo proponente, tampouco nas instâncias colegiadas.

Diante dessas fragilidades institucionais, a análise das entrevistas dos delegados do Colegiado Territorial revelou que, com frequência, a aprovação de projetos financiados pelo Pronat passou por acordos de reciprocidade estabelecidos entre organizações da sociedade civil. Geralmente, os projetos eram colocados em apreciação nas reuniões do Codeter sem o devido parecer técnico, o que facilitava a aprovação por esse tipo de procedimento. O apoio na aprovação de projeto pleiteado por uma determinada organização significava um compromisso da mesma em retribuir no momento de aprovar projetos apresentados pelas organizações apoiadoras.

As entrevistas realizadas com delegados do Codeter e o estudo da Matriz de Ações do Pronat referente ao período de 2003 a 2015 sugerem que, no Meio Oeste Contestado, o planejamento para aplicação territorializada das ações se deu de forma precária e sem a devida demonstração de viabilidade técnica. De maneira geral, prevaleceu o financiamento de projetos que assistem grupos sociais de municípios cuja prefeitura se responsabilizou pelos trâmites burocráticos e pela contrapartida financeira. A falta de uma institucionalidade jurídica interferiu no cumprimento das orientações da política pública, pois preponderou o caráter municipalista na efetivação das ações do Pronat no território pesquisado. Além disso, 
para a maioria dos delegados do Codeter e assessores territoriais entrevistados, os prefeitos não admitiam interferências nas decisões relacionadas às políticas implementadas, logo não participavam do Colegiado Territorial, espaço onde a aplicação territorializada das ações do Pronat poderia ter sido articulada. De acordo com Niederle (2014, p. 126), os prefeitos justificam essa atitude com o argumento de que “[...] é lá no município que a vida e a política acontecem".

\section{APLICAÇÃO DOS RECURSOS FINANCEIROS DO PRONAT}

Neste tópico, analisamos a aplicação dos recursos financeiros do Pronat, bem como o "jogo de atores" e as dinâmicas que a influenciaram. O Quadro 01, com base na Matriz de Ações do Pronat, apresenta o valor financiado pelo MDA entre 2003 e 2015 em cada município das três Associação de Municípios que integraram o Território Meio Oeste Contestado. Salientamos que nem todos os municípios da AMMOC e da AMNoroeste fizeram parte do recorte espacial adotado pela política territorial do MDA. 
Quadro 01: Valor dos objetos financiados pelo Pronat entre 2003 e 2015 nas três AM que integram o Território Meio Oeste Contestado

\begin{tabular}{|c|c|c|c|c|c|}
\hline \multicolumn{2}{|l|}{ AMAI } & \multicolumn{2}{|l|}{ AMMOC } & \multicolumn{2}{|l|}{ AMNoroeste } \\
\hline Município & $\mathbf{R} \$$ & Município & $\mathbf{R} \$$ & Município & $\mathbf{R} \$$ \\
\hline $\begin{array}{l}\text { Abelardo } \\
\text { Luz }\end{array}$ & $3.847 .094,52$ & Água Doce & $467.231,51$ & Cor. Martins & $1.226 .692,85$ \\
\hline Bom Jesus & 0 & Capinzal & $393.750,26$ & Galvão & $367.966,14$ \\
\hline Entre Rios & $213.395,35$ & Catanduvas & $439.566,46$ & Jupiá & $602.150,88$ \\
\hline Ipuaçu & 0 & Erval Velho & $39.018,56$ & - & - \\
\hline $\begin{array}{l}\text { Faxinal } \\
\text { Guedes }\end{array}$ & $225.573,11$ & Herval d'Oeste & 0 & - & - \\
\hline $\begin{array}{l}\text { Lajeado } \\
\text { Grande }\end{array}$ & $240.000,00$ & Ibicaré & $110.000,00$ & - & - \\
\hline Marema & $103.962,60$ & Joaçaba & $441.297,84$ & - & - \\
\hline Ouro Verde & $247.300,00$ & Lacerdópolis & $122.500,00$ & - & - \\
\hline $\begin{array}{l}\text { Passos } \\
\text { Maia }\end{array}$ & $202.276,20$ & Luzerna & 0 & - & - \\
\hline $\begin{array}{l}\text { Ponte } \\
\text { Serrada }\end{array}$ & $273.522,69$ & Ouro & $804.414,91$ & - & - \\
\hline $\begin{array}{l}\text { São } \\
\text { Domingos }\end{array}$ & $2.909 .837,59$ & Treze Tílias & $45.578,94$ & - & - \\
\hline Vargeão & $153.300,00$ & Vargem Bonita & $207.779,00$ & - & - \\
\hline Xanxerê & $792.744,08$ & - & - & - & - \\
\hline Xaxim & $763.024,81$ & - & - & - & - \\
\hline $\begin{array}{l}\text { Total por } \\
\text { AM }\end{array}$ & 9.972.030,95 & & 3.071.137,48 & & $2.196 .809,87$ \\
\hline \multicolumn{5}{|c|}{ Total no Território } & $15.239 .978,30$ \\
\hline
\end{tabular}

Fonte: Adaptado com base nas informações obtidas na Matriz de Ações do Pronat.

De acordo com o Quadro 01, entre 2003 e 2015, o valor total de recursos financeiros aplicados no Território Meio Oeste Contestado totalizou R\$ 15.239.978,3011. Dos 29 municípios que integram o Território, 25 foram proponentes de projetos, sendo que Bom Jesus, Herval d'Oeste, Ipuaçu e Luzerna não foram beneficiados por nenhuma ação. Destes, apenas Ipuaçu manteve uma participação mais recorrente no Codeter, enquanto a presença dos demais foi bastante inconstante.

No que concerne ao acesso aos recursos financeiros por AM, destacam-se a AMAI $(\mathrm{R} \$ 9.972 .030,95)$ e a AMNoroeste $(\mathrm{R} \$ 2.196 .809,87)$, que juntas angariaram quase $80 \%$ do montante (Quadro 01). Essas duas AM possuíam como característica comum à ativa participação de atores da sociedade civil ligados à agricultura familiar tanto nas

11 Neste montante, não está incluído o valor das contrapartidas financeiras aportadas pelas prefeituras municipais ou por meio de emendas parlamentares, pois estas informações não foram disponibilizadas na Matriz de Ações. 
administrações municipais quanto no Codeter. Esses atores possuíam articulações com os deputados federais e senadores e reivindicaram a destinação de recursos financeiros complementares de emendas parlamentares que serviram de contrapartida ao valor disponibilizado pelo MDA. Ademais, os delegados dessas duas AM estabeleceram acordos de reciprocidades, conforme comentado anteriormente. Por sua vez, a AMMOC ficou com um pouco mais de $20 \%$ dos recursos financeiros ( $\mathrm{R} \$ 3.071 .137,48)$. Os delegados da AMMOC eram predominantemente da esfera governamental, ou seja, não eram os agricultores familiares diretamente interessados no financiamento de projeto. Como já mencionamos, em muitos casos, o tempo entre a divulgação dos recursos financeiros e a apresentação dos projetos era curto e não condizia com o tempo que os atores governamentais precisavam para organizar atores da sociedade civil e apresentar a proposta. Essa é uma das principais causas de esta AM ter recebido menos recursos financeiros.

A análise dos projetos do Pronat, implementados entre 2003 e 2015 no Território Meio Oeste Contestado, indica que existe uma dicotomia no que concerne ao objeto financiado e a forma de acesso aos recursos. Entre 2003 e 2008, foram financiados, principalmente, agroindústrias, equipamentos para as agroindústrias e a construção de centros de comercialização de produtos da agricultura familiar. Esses projetos foram propostos pelos grupos de agricultores familiares, discutidos e aprovados no Codeter e a contrapartida financeira necessária foi negociada com as prefeituras.

Entre 2009 e 2015, prevaleceu o financiamento de infraestrutura como caminhões, equipamentos para distribuição de calcário, retroescavadeira, tratores, entre outros. Segundo assessores territoriais que atuaram na esfera federal, estadual e territorial e delegados do Codeter, praticamente todos os recursos que financiaram esses projetos são oriundos de emendas parlamentares, cujas negociações foram realizadas entre os prefeitos e os deputados federais, sem a devida discussão e aprovação no Colegiado Territorial. Isso ocorreu em função de o Tribunal de Contas da União entender que o repasse de equipamentos e estruturas produtivas por meio de contrato de repasse para instituições da sociedade civil era ilegal. Diante dessa situação, o MDA orientou que os recursos do Pronat fossem investidos nas prefeituras, desde que atendesse os agricultores familiares.

A aplicação de recursos financeiros do Pronat sem discussão prévia no Codeter desrespeitou um dos princípios básicos da territorialização da ação pública, que consiste na 
participação de atores governamentais e da sociedade civil no seu processo de gestão social. Nesse sentido, para Leite e Wesz Júnior (2011), quando a contrapartida dos projetos financiados pelo Pronat provém de emendas parlamentares, provavelmente, são financiados projetos de interesse do parlamentar ou de grupos políticos municipais ligados a ele, sem considerar os preceitos da territorialização das políticas públicas.

Outro aspecto a ser considerado nesta análise diz respeito à integração dos povos de comunidades tradicionais prevista na política de desenvolvimento territorial do MDA. Essa política considerava os povos tradicionais como público prioritário a ser atendido pelas suas políticas, todavia, no Meio Oeste Contestado, os indígenas e os agricultores caboclos ${ }^{12}$ que, de maneira geral, são os atores sociais mais empobrecidos no meio rural da região estudada (TECCHIO et. al., 2019; 2018) não acessaram recursos do Pronat.

Segundo Cazella (2006), as ações públicas de desenvolvimento rural elaboradas como alternativa ao modelo produtivista, geralmente, beneficiam agricultores familiares consolidados socioeconomicamente. As ações referentes a tais políticas concentram-se em torno do que denominou de "três agros" - agroecologia, agroturismo e agroindústria familiar. Esse autor não contesta a importância social dessas estratégias, mas sim sua eficácia em beneficiar as populações rurais mais pobres. Para Delgado e Grisa (2014), as populações pobres não foram beneficiadas pelo Pronat, entre outros motivos, pelo fato deste Programa não ter conseguido superar o paradigma de intervenção pública do Proinf ao qual sucedeu. Com isso, o rural presente nos Codeter continuou limitado à representação de agricultores familiares ligados a movimentos sociais, sindicatos e cooperativas. Não obstante, essas constatações foram identificadas em diversos territórios rurais de identidade no Brasil (LEITE, 2013b).

\section{A TERRITORIALIZAÇÃO DAS AÇÕES DO PTC}

Diante da complexidade para planejar a aplicação territorializada das ações do Programa Territórios da Cidadania, o Codeter do Meio Oeste Contestado buscou, entre os representantes governamentais, além de profissionais das áreas da saúde, da educação e da

\footnotetext{
12 Os caboclos são originários da miscigenação étnica entre índios, luso-brasileiros e ex-escravos negros. Embora não sejam reconhecidos pelo Estado como "povos tradicionais", possuem fortes característica para tanto, como evidenciou Podelesky (2014).
} 
assistência social - conforme o novo programa territorial recomendava -, a participação dos prefeitos. Dos 29 prefeitos, oito participaram no início da implementação do PTC, mas se desmobilizaram logo em seguida. Na opinião dos delegados e assessores territoriais, a desmotivação se deve, em parte, à falta de entendimento de qual seria a respectiva função a ser desempenhada no Colegiado Territorial.

Provavelmente, os gestores públicos não viram mudanças na forma de captação de recursos públicos no Governo Federal após a implementação do PTC, pois as políticas públicas informadas na Matriz de Ações já vinham sendo executadas nos município antes da criação desse Programa. Na prática, a forma de acessar os recursos públicos iria continuar da mesma maneira, independentemente de os gestores públicos participarem ou não no Codeter, pois o acesso às verbas não dependia da sua aprovação no Codeter, como era o procedimento de acesso ao Pronat. Além disso, conforme sugerem os assessores territoriais, não houve suficiente capacitação para que os delegados e os gestores públicos entendessem que, além das funções que já vinham desempenhando relacionadas ao Pronat, deveriam fazer a gestão social e planejar a aplicação territorializada dos recursos financeiros informados na Matriz de Ações do PTC. De acordo com Cazella, Zimmermann e Leite (2013), essa deficiência deve-se à falta de tradição no País sobre planejamento em escala supramunicipal. Logo, as políticas territorializadas pecaram por não prever um tempo mínimo e ações de formação para que os atores implicados com o processo se apropriassem dos instrumentos de gestão.

Nos municípios pesquisados, quem toma as decisões concernentes à implementação de políticas públicas é o prefeito, assessorado por sua equipe de governo. Com o propósito de captar recursos financeiros nos Governos Federal e Estadual, a maioria das prefeituras contratavam empresas de assessoria existentes na região ou mesmo fora dela. Estas, na maioria dos casos, informavam os municípios sobre a disponibilidade de recursos financeiros por meio de editais.

Não obstante, nem todas as prefeituras dos municípios do Meio Oeste Contestado recorreram a esse tipo de assessoria para captar recursos financeiros. Algumas delas adotaram outro dispositivo, que consiste em recorrer ao apoio das equipes de assessoria dos deputados federais e estaduais e dos senadores das mesmas siglas partidárias da coligação que compõem a gestão municipal. Nessa modalidade, as demandas eram enviadas ou entregues pessoalmente a deputados e senadores. Como ocorre com as emendas parlamentares, cabe a 
esses políticos priorizarem os municípios e as áreas a serem beneficiadas financeiramente. Porém, o fator que determinava a decisão sobre a aplicação de políticas públicas era a disponibilidade de recursos necessários à contrapartida financeira, que é de responsabilidade das prefeituras, bem como a capacidade de executar os demais trâmites legais.

Ao serem indagados sobre como ocorria o planejamento das políticas públicas direcionadas às populações pobres, quase todos os gestores públicos responderam que essas populações são assistidas pelo Estado por meio das políticas de saúde, educação, assistência social e ações que promovem o aumento de emprego. Nenhum município dispõe de planejamento ou políticas específicas de enfrentamento da pobreza, pois os gestores públicos atribuem essa tarefa exclusivamente aos Governos Federal e Estadual, alegando que os orçamentos municipais não comportam tais ações.

O Governo Federal tinha uma orientação política geral de facilitar a liberação de recursos financeiros para os municípios integrantes do PTC, porém, isso ficava a cargo dos Ministérios e Secretarias, condicionado à ação dos gestores federais de cada política (LEITE, 2013a). Além disso, os municípios que integravam os territórios da cidadania recebiam o "selo PTC", que significa, na prática, que agências e bancos governamentais aumentaram o interesse por tais municípios, devido ao prestígio que passaram a ter em função das melhorias no acesso às políticas públicas (DELGADO, GRISA, 2013; 2014). Entre os gestores públicos do Território Meio Oeste Contestado, há divergências a esse respeito. Em geral, os que eram mais alinhados partidariamente ao Governo Federal enfatizavam nas justificativas dos projetos que faziam parte do Território da Cidadania Meio Oeste Contestado, pois havia uma priorização na análise da proposta e na liberação das verbas. Já os gestores públicos que eram antagônicos ao Governo Federal afirmaram que o fato de o município pertencer a um território de cidadania não influenciava na obtenção de recursos financeiros na esfera federal. Isso significa certa negação política das ações dos "adversários”, pois esses gestores declaram que citavam, nas justificativas dos projetos enviados ao Governo Federal, o fato de o município pertencer ao território da cidadania Meio Oeste Contestado.

As ações territorializadas, principalmente as do PTC, contribuíram, de modo geral, para a melhoria das condições de vida das populações pobres do Meio Oeste Contestado, na opinião da maioria dos atores entrevistados, em decorrência do maior acesso a serviços públicos e direitos sociais. Além dessas ações, as condições de vida da população pobre 
foram melhoradas, segundo Maluf (2013), a um conjunto de ações implementadas desde o início do governo Lula, entre elas, a valorização do salário mínimo, aumento dos benefícios da seguridade social, investimentos públicos que estimularam a geração de empregos, ampliação significativa da transferência de renda e apoio à agricultura familiar.

\section{CONSIDERAÇÕES FINAIS}

O reconhecimento dos territórios como unidade de aplicação de recursos financeiros por meio do Pronat representou um avanço. Porém, a inexistência de um marco jurídico para o território, comprometeu a liberdade de decisão das instituições territoriais. Isso obrigou essas instituições e os atores sociais que delas participavam a negociarem com os governos estaduais e, principalmente, com as prefeituras municipais o acesso a recursos de infraestrutura disponibilizados pelo Pronat, bem como as responsabilidades sobre os trâmites burocráticos e a contrapartida financeira que se faz necessária.

Por sua vez, nem todas as prefeituras dispunham de recursos necessários - inclusive por inadimplência de prestações de conta de outras naturezas - para atender às demandas por investimentos. Para os beneficiários potenciais de um projeto, a disponibilidade de infraestrutura territorial por meio de um contrato de repasse não garantiu segurança de usufruto, uma vez que o patrimônio tornava-se propriedade das prefeituras e seus gestores ou o utilizam conforme suas necessidades e interesses ou rompiam acordos firmados por gestores públicos que os antecederam. A "incompletude" da política é um dos fatores responsáveis, então, pela manutenção do caráter municipal dos projetos financiados pelo Pronat, uma vez que a infraestrutura rural ficou alocada, em quase todos os casos, no município com o qual foi firmado o contrato de repasse, contrariando a orientação da política territorial, de implementar projetos intermunicipais.

A estrutura rural financiada pelo Pronat no Meio Oeste Contestado entre 2003 e 2015, beneficiou agricultores familiares inseridos em mercados e organizados em cooperativas de produção, sindicatos e movimentos sociais. As populações tradicionais caboclas e indígenas praticamente não mantiveram vínculos com o sistema de gestão da política e, desse modo, não participaram do Codeter. Não observamos nenhuma ação ou interesse das esferas do poder público - federal, estadual e municipal - em tratar essas populações de forma 
diferenciada para que se habilitassem a participar do Colegiado e capitaneassem recursos do Pronat para financiar projetos dos seus interesses.

A concepção do PTC baseada na abordagem territorial implicou na necessidade de planejamento das ações nas esferas nacional e territorial para o enfrentamento da pobreza em espaços precisos. No Meio Oeste Contestado, não houve suficiente capacitação ou debate para que os delegados do Território e os gestores públicos entendessem o uso da Matriz de Ações como um instrumento de planejamento de ações setoriais a serem implementadas de maneira territorializada. Assim sendo, as ações do PTC não acompanharam inteiramente a inovação conceitual incorporada na ideia da aplicação territorializada de ações públicas, uma vez que os mecanismos de acesso e de liberação dos recursos financeiros não foram alterados adequadamente e continuaram praticamente os mesmos do período anterior à sua existência.

Ao término desta análise convém retomar a questão formulada no subtítulo do artigo. Em síntese, a territorialização da ação pública não foi eficaz enquanto ferramenta para promover a inserção produtiva das famílias rurais pobres. No entanto, a criação dos territórios como unidade de articulação para a aplicação territorializada de ações públicas com a participação de atores governamentais e da sociedade civil na sua gestão social foi uma importante inovação no que concerne à intervenção pública governamental, sobretudo, em ações de natureza social, com destaque para as melhorias em serviços de saúde, educação e assistência social, voltadas para as populações pobres de municípios rurais. Essa inovação institucional necessitaria ser aprimorada no que diz respeito à divulgação e à compreensão pelos atores institucionais participantes - de sua abordagem conceitual e metodológica e dos mecanismos de operacionalização das ações públicas.

A extinção do MDA em maio de 2016, todavia, implicou na transferência inicial das funções da SDT, que era responsável pelo Pronat e pelo PTC, para a Casa Civil. Posteriormente, ficou a cargo da Secretaria de Agricultura Familiar e Cooperativismo do Ministério da Agricultura, Pecuária e Abastecimento, que abrigou algumas incumbências do antigo MDA, porém, não tem nenhum departamento voltado para o desenvolvimento territorial. Teve-se, portanto, um processo mais amplo de desmonte dessa política, cujos, efeitos imediatos é que, desde o final de 2016, não houve destinação de recursos financeiros para o Pronat, tampouco aos territórios da cidadania. De todo modo, trata-se, certamente, de 
um processo de aprendizagem social que serve de base para novas experiências de natureza semelhante, que possam ser operadas no futuro.

A título de continuidade de pesquisas empíricas correlacionadas ao tema do desenvolvimento territorial em zonas rurais sugere-se a análise de três aspectos, que este estudo ou não contemplou ou o fez de forma preliminar. O primeiro se refere ao destino dos empreendimentos financiados com recursos do Pronat, em especial das agroindústrias. Concebidas para beneficiar diversas famílias de agricultores de distintos municípios do território, parte das agroindústrias pode ainda estar sem uso, mas convém também investigar os casos que se encontram em atividade por iniciativas locais que se diferenciam dos propósitos iniciais. Um segundo tema que este estudo revelou, mas não se teve condições de aprofundar, diz respeito às empresas privadas que assessoram as administrações municipais nas áreas de planejamento e captação de recursos financeiros de outras instâncias governamentais. Conhecer seus métodos de planejamento e sistemas de acesso a informações representam assuntos praticamente inexistentes nos estudos sobre desenvolvimento territorial. E o terceiro se refere a iniciativas de parcerias intermunicipais por meio da constituição de consórcios públicos no sentido de perceber, em que medida, as ações dos programas aqui analisados influenciaram a constituição desse tipo de parceria ou se trata de um domínio de ação pública cuja origem é completamente distinta da que foi investigada neste artigo.

\section{REFERÊNCIAS}

ABRAMOVAY, R. Conselhos além dos limites. Estudos avançados, São Paulo, SP, v. 15, n. 43, p. 121-140, 2001.

BARBOSA, R. S.; ZIMMERMANN, S. A.; TECCHIO, A. Desenvolvimento territorial e pobreza rural no Território da Cidadania Serra Geral (MG). In: LEITE, S. P. (Org.). Políticas de Desenvolvimento Territorial e Enfrentamento da Pobreza Rural no Brasil: Estudos de caso. Brasília: IICA, v. 20, 2013. p. 171-205.

BONNAL, P. Referências e considerações para o estudo e a atuação dos programas de desenvolvimento territorial (PRONAT e PTC) na perspectiva da redução da pobreza em territórios rurais. In: LEITE, S. P. (Org.). Políticas de Desenvolvimento Territorial e Enfrentamento da Pobreza Rural no Brasil. Brasília: IICA, 2013, v. 19. p. 33-56.

BONNAL, P.; KATO, K. O processo contemporâneo de territorialização de políticas e ações públicas no meio rural brasileiro. In: MIRANDA, C.; TIBURCIO, B. (Org.). 
Políticas Públicas, Atores Sociais e Desenvolvimento Territorial no Brasil. Brasília: IICA, 2011, v. 14. p. 61-88.

CAZELLA, A. A. Contribuições metodológicas da sócio-antropologia para o desenvolvimento territorial sustentável. Eisforia, Florianópolis, SC, v. 4, n. especial, p. 225-247, 2006.

CAZELLA, A. A.; ZIMMERMANN, S. A.; LEITE, S. P. A gestão do Programa Territórios da Cidadania no Brasil: análise das ações e políticas implementadas. Perspectivas Rurales, $\mathrm{n}^{\circ} 22$, p. 71-107, 2013.

DELGADO, N. G; GRISA, C. Institucionalidades, Governança e Projetos Territoriais na Política de Desenvolvimento Rural no Brasil. In: LEITE, S. P. (Org.). Políticas de Desenvolvimento Territorial e Enfrentamento da Pobreza Rural no Brasil. Brasília: IICA, 2013, v. 19. p. 239-288.

. Políticas de desenvolvimento territorial e pobreza rural no Brasil: análise das institucionalidades e da governança. Estudos Sociedade e Agricultura, Rio de Janeiro, RJ, v. 22, n. 1, p. 132-163, 2014.

Governança territorial, dinâmica institucional e protagonismo social territorial: revisitando um percurso metodológico seguido pelo OPPA/CPDA no marco dos estudos territoriais. Revista em Gestão, Inovação e Sustentabilidade, Brasília, DF, v. 1, n. 1, p. 48-66, 2015.

DELGADO, N. G.; LEITE, S. P. Políticas de desenvolvimento territorial no meio rural brasileiro: novas institucionalidades e protagonismo dos atores. Revista de Ciências Sociais. Rio de Janeiro, RJ, v. 54, n. 2, 2011.

DOUILLET, A. C. Les politiques contractuelles de développement local en milieu rural. In: FAURE, A.; DOUILLET, A. C. (Dir.). La action publique et la question territoriale. Grenoble: Presses Universitaires de Grenoble, 2005. p. 75-91.

DURAN, P. Territorialisation. In: Dictionnaire des politiques territoriales. PASQUIER, R.; GUIGNER, S.; COLE, A. (Dir.). Paris: Presses de Sciences Po, Collection Références, 2011. p. 475-482.

FAVARETO, A. As tentativas de adoção da abordagem territorial do desenvolvimento rural - lições para uma nova geração de políticas públicas. In: PIRAUX, M.; CANIELLO, M. (Org.). Dossiê: Território, sustentabilidade e ação pública. Raízes, Campina Grande, PB, v. 28, n. 1 e 2 e v. 29, n. 1, p. 52-62, 2010.

FAURE, A. Action publique territoriale. In: Dictionnaire des politiques territoriales. PASQUIER, R.; GUIGNER, S.; COLE, A. (Dir.). Paris: Presses de Sciences Po, Collection Références, 2011. p. 27-33. 
HASSENTEUFEL, P. Think social, act local: la territorialisation comme réponse à la "crise de l'état-providence"? Politiques et management public, Cachan, v. 16, n. 3, p. 1-11,1998.

INSTITUTO BRASILEIRO DE GEOGRAFIA E ESTATÍSTICA - IBGE. Geociências, Rio de Janeiro: IBGE, 2017.

JAILLET, M. Contre le territoire, la bonne distance. In: Territoires, territorialité, territorialisation: controverses et perspectives. VANIER, M. (Dir.) Rennes: Presses Universitaires de Rennes, 2009. p. 115-121.

LASCOUMES, P.; LE GALÈS. P. Sociologie de l'action publique. 2e éd. Paris: Armand Colin, 2012. $127 \mathrm{p}$.

LEITE, S. P.; WESZ JUNIOR, V. J. O financiamento da política de desenvolvimento territorial: uma análise do PRONAT e do Programa Território da Cidadania. In: MIRANDA, C.; TIBURCIO, B. (Org.). Políticas Públicas, Atores Sociais e Desenvolvimento Territorial no Brasil. Brasília: IICA, 2011. v. 14, p. 169-186.

LEITE, S. P. (Org.). Políticas de Desenvolvimento Territorial e Enfrentamento da Pobreza Rural no Brasil. Brasília: IICA, 2013a, v.19. 359 p.

Políticas de Desenvolvimento Territorial e Enfrentamento da Pobreza Rural no Brasil: Estudos de Casos. Brasília: IICA, 2013b, v. 20. 308 p.

MAILLARD, J.; ROCHÉ, S. La sécurité entre secteurs et territoires. In: FAURE, A.; DOUILLET, A. C. (Dir.). La action publique et la question territoriale. Grenoble: Presses Universitaires de Grenoble, 2005. p. 33-51.

MEDEIROS, L. S; DIAS, M. M. Marco jurídico-normativo para o desenvolvimento rural com enfoque territorial. In: MIRANDA, C.; TIBURCIO, B. (Org.). Políticas Públicas, Atores Sociais e Desenvolvimento Territorial no Brasil. Brasília: IICA, 2011, v. 14. p. 197-230.

MALUF, R. S. Elementos para uma agenda pública de enfrentamento da pobreza e inclusão sócioprodutiva no meio rural na ótica do desenvolvimento territorial sustentável. In: LEITE, S. P. (Org.). Políticas de Desenvolvimento Territorial e Enfrentamento da Pobreza Rural no Brasil. Brasília: IICA, 2013, v.19. p. 57-88.

MATTEI, L.; CAZELLA, A. A. Planejamento e gestão do Pronaf Infra-estrutura e Serviços: evidências a partir do Estado de Santa Catarina. In: SCHNEIDER, S.; SILVA, M. K.; MARQUES, P. E. M. (Org.). Políticas e Participação Social no Brasil Rural. 2. ed. Porto Alegre: Editora da URGS, 2009. p. 175-199. 
MINISTÉRIO DO DESENVOLVIMENTO AGRÁRIO - MDA. Referência para a gestão social dos territórios rurais: guia para a organização social. Documento de apoio n 3 . Brasília, 2006.

Referências para a gestão social de territórios rurais. Documento institucional no 3. Brasília, 2005.

NIERDERLE, P. A. Política local e a trama das relações de poder no desenvolvimento territorial. In: Participação, Territórios e Cidadania: um olhar sobre a política territorial no Brasil. CAVALCANTI, J. S. B.; WANDERLEY, M. N. B.; NIERDERLE, P. A. (Org.). 2014. p. 103-134.

OLIVEIRA, L. Z.; CAZELLA, A. A.; TECCHIO, A.; MIRESKI, M. C. Ações da política de desenvolvimento territorial para superar a pobreza rural: estudo de caso no território Meio Oeste Contestado (SC). Rev. Bras. de Gest. e Desenv. Regional, v. 11, n. 1, p. 323348, 2015.

PODELESKI, O. S. Estratégias de reprodução social de populações remanescentes do Contestado: o caso da comunidade de Taquaruçu, no Meio-Oeste de Santa Catarina. 2014. 157 p. Dissertação (Mestrado em Agroecossistemas) - Universidade Federal de Santa Catarina, Florianópolis, SC, 2014.

ROMANO, J. O. Política nas políticas: um olhar sobre a agricultura brasileira. Rio de Janeiro: Mauad X, 2009. 308 p.

SÉCHET, R. Espaces et pauvretés: la géographie interrogée. Paris: L’Harmattan, 1996. $213 \mathrm{p}$.

TECCHIO, A.; CORTES, G.; CAZELLA, A. A.; BÚRIGO, F. L.; MEDEIROS, M. Territorialização da ação pública de enfrentamento da pobreza: mudanças institucionais e gestão social no Meio Oeste Contestado (SC). In: Gestão e dinâmicas em desenvolvimento territorial. PEREFÁN, M. E. V.; GRISA, C.; TARTARUGA, I. P.; RAMÍRESZ-MIRANDA, C. A. (Org.). 2018. p. 391-406.

TECCHIO, A.; CAZELLA, A. A.; SABOURIN, E; CORTES, G. Estratégias alimentares de famílias pobres no Oeste de Santa Catarina. Redes: Revista de Desenvolvimento Regional, v. 24, n. 3, p. 217-240. 2019. 